\title{
Acute sleep deprivation has no lasting effects on the human antibody titer response following a novel influenza $\mathrm{A} \mathrm{H} 1 \mathrm{~N} 1$ virus vaccination
}

\author{
Christian Benedict $^{1 *}$, Maria Brytting ${ }^{2}$, Agneta Markström³ ${ }^{3}$ Jan-Erik Broman ${ }^{3}$ and Helgi Birgir Schiöth ${ }^{1}$
}

\begin{abstract}
Background: Experimental studies in humans have yielded evidence that adaptive immune function, including the production of antigen-specific antibodies, is distinctly impaired when sleep is deprived at the time of first antigen exposure. Here we examined the effects of a regular 24- hour sleep-wake cycle (including 8 hours of nocturnal sleep) and a 24-hour period of continuous wakefulness on the 7-week antibody production in 11 males and 13 females in response to the H1N1 (swine flu) virus vaccination. The specific antibody titer in serum was assayed by the hemagglutination inhibition test on the days 5, 10, 17, and 52 following vaccination.

Results: In comparison to the sleep group, sleep-deprived males but not females had reduced serum concentration of H1N1-specific antibodies five days after vaccination, whereas antibody titers at later time points did not differ between the conditions.

Conclusions: These findings concur with the notion that sleep is a supportive influence in the very early stage of an adaptive immune response to a viral antigen. However, our results do not support the view that acute sleep deprivation has lasting effects on the human antibody titer response to influenza vaccination.
\end{abstract}

\section{Background}

The lack of time to sleep is a hallmark of modern living, and it is commonly assumed that in the long run this makes us unwell. This assumption is supported by experimental data showing that acute sleep deprivation decreases or decelerates the production of antigen- specific antibodies if sleep is interrupted in the night following the vaccination $[1,2]$, indicating that poor sleep patterns potentially counteract the process of effective adaptive immune responses. Sleep is assumed to regulate immune function primarily by fostering adaptive immune responses [3-5]. In the present study, we investigated a 7-week antibody titer in males and females in response to a novel influenza A H1N1 virus (swine flu) vaccination and measured the effects of sleep in those who had a single night of sleep deprivation versus no sleep deprivation.

\footnotetext{
* Correspondence: christian.benedict@neuro.uu.se

'Department of Neuroscience, Uppsala University, Uppsala, Sweden

Full list of author information is available at the end of the article
}

\section{Results}

Hemagglutination inhibition antibody titer against the H1N1 virus

Overall, the antibody production did not differ between treatments and/or sexes. ( $\mathrm{P} \geq 0.302$ for all KruskalWallis comparisons, Figure $1 \mathrm{AB})$. However, five days after vaccination, the antibody response associated with sleep deprivation was approximately $60 \%$ lower in males than that measured in those of the sleep group ( $\mathrm{P} \leq$ 0.050, two-tailed Mann-Whitney test; $\mathrm{P} \leq 0.037$ for the Kruskal-Wallis comparison; Figure 1C). In contrast, the immune response in women was generally not influenced by sleep deprivation ( $P \geq 0.171$ for all KruskalWallis comparisons, Figure 1D).

\section{Sleep}

The EEG recordings revealed a normal sleep pattern (in min \pm SEM; Total sleep time: $470 \pm 27$; Slow-wave sleep, $145 \pm 14$; Rapid-eye movement sleep, $81 \pm 11$ ). Data gathered using sleep diaries (recording the time of sleep) during the first 10 days after $\mathrm{H} 1 \mathrm{~N} 1$ vaccination ensured the continuation of regular sleep start times (ie.,

\section{C) Biomed Central}




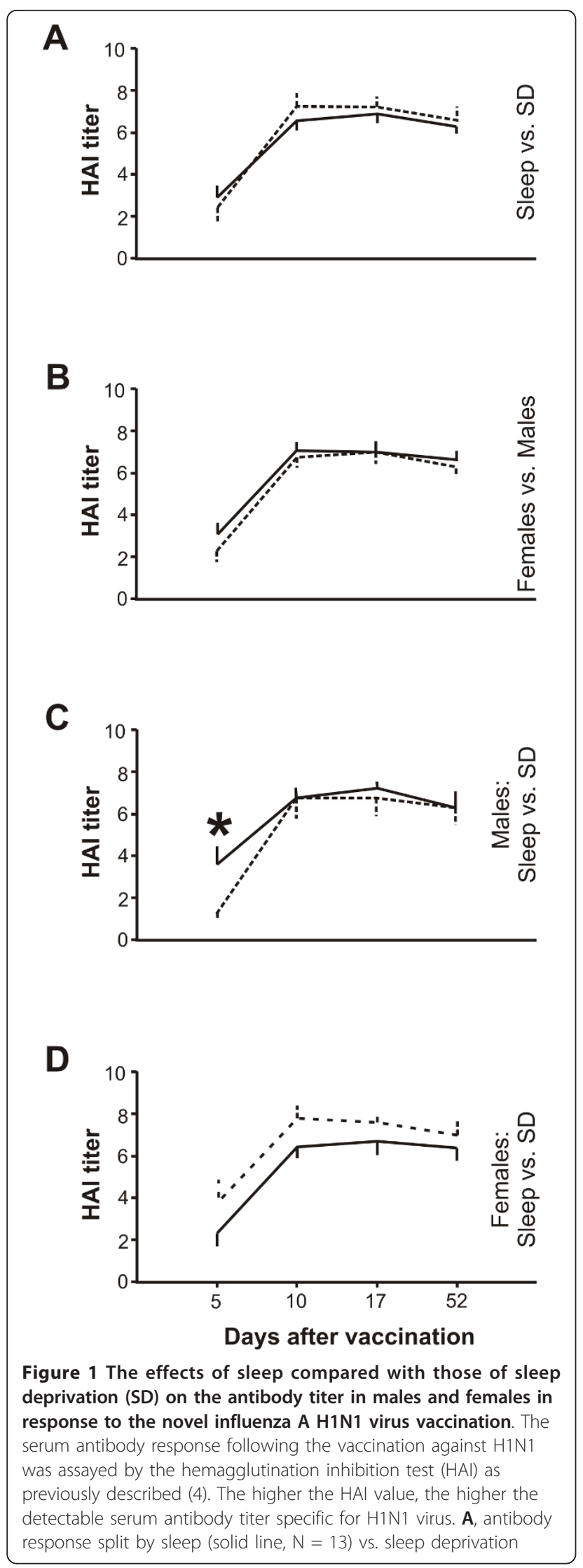

(dashed line, $\mathrm{N}=11$ ). $\mathbf{B}$, antibody response split by females (solid line, $N=13$ ) vs. males (dashed line, $N=11$ ). $\mathbf{C}$, antibody response in males split by sleep (solid line, $\mathrm{N}=5$ ) vs. sleep deprivation (dashed line, $N=6$ ). $\mathbf{D}$, antibody response in females split by sleep (solid line, $N=8$ ) vs. sleep deprivation (dashed line, $N=5$ ). Differences between (sub)groups were analyzed using the KruskalWallis test, with Mann-Whitney $U$ post hoc testing, and a $P$ value $\leq$ 0.05 was considered statistically significant. All data are presented as means \pm SEM.

between 22:00 PM and 8:00 AM the next morning) in both conditions.

\section{Discussion}

Acute sleep deprivation impaired the early immune response to $\mathrm{H} 1 \mathrm{~N} 1$ virus in males, despite prolonged periods of sleep recovery after antigen exposure. In contrast, in females, the production of antibodies specific for the swine flu virus was not influenced by sleep loss. These results underline the relevance of sleep for supporting immune functions [3-5].

Our results suggest that acute sleep deprivation is associated with a delayed induction of adaptive immune response to H1N1 virus in males that is consistent with previous data. That is, interrupted sleep at the time of first virus exposure is followed by a slower increase in specific antibody titers relative to that following undisturbed sleep [1]. Factors important for an effective adaptive immune response show very concordant changes under sleep deprivation $[4,6]$. For instance, the production of growth hormone normally peaks during early sleep periods [7], and this effect is suppressed by sleep deprivation [8]. This hormone stimulates immune function directly in that many immune cells possess receptors for growth hormone [9]. Further, the secretion of cytokines involved in the adaptive immune response is downregulated by sleep loss (e.g. Interleukin-2 and Interleukin-7; $[10,11])$. Such hormonal changes associated with interrupted sleep might have contributed to the decelerated immune response to $\mathrm{H} 1 \mathrm{~N} 1$ that was observed in males but not females in our study. Interestingly, in a recently published study, a lipopolysaccharide-induced immune response following acute sleep loss has been shown to induce distinct sex differences inasmuch as sleep-deprived females showed increased production of proinflammatory cytokines compared to response in sleep-deprived males [12]. However, there are also other candidate mechanisms that may account for the impaired antibody titer response in sleepdeprived males seen on day 5 . For instance, compared with sleep, sleep loss is associated with a striking decrease in the number of myeloid dendritic cell precursors [13]. These cells play a major role for the initiation 
of adaptive immune responses [14]. Further it might be that the impaired effect of sleep loss on the early antibody titer response to the $\mathrm{H} 1 \mathrm{~N} 1$ vaccination was due to a delayed migration of antibody titer producing $\mathrm{B}$ cells into the blood.

At the first glance, the clinical relevance of our findings is somewhat questionable because the only difference in specific antibody titers is 5 days after vaccination in males only and titers even out thereafter, which in the end results in same possible protection in sleep deprived and regular sleep subjects. In contrast, other studies with a similar study design showed profound effects of sleep deprivation on specific antibody titers at later time points, e.g. a 2-fold higher hepatitis A titer at day 28 post immunization in regular sleep subjects as compared to sleep deprived men [2]. Nevertheless, in a sort of external validation of our results, previous observations revealed that partial sleep deprivation in the time of vaccination against a seasonal influenza virus induced differences in specific antibody titers during early periods (ie., after 10 days) but not during late periods (ie., after 28 days) of the adaptive immune response [1]. One explanation for the discrepancy in results among these studies could be that the effect size of sleep deprivation on adaptive immune responses is antigen- specific.

\section{Limitations}

Due to the similarity of the antigen with other influenza strains there might be the possibility that the history of influenza vaccination plays a profound role in the response to $\mathrm{H} 1 \mathrm{~N} 1$ vaccine. In this respect, the major shortcoming of the present study is that no HAI titers were determined before vaccination to exclude possible cross-reactivity of antibodies possibly already present. Although it was vital that participants reported, in a thorough interview, to have been free of major influenza-like symptoms in the past 6 months, we thus cannot exclude that there were any baseline differences in HAI titers before vaccination. However, given the age of the subjects (around 20 years) it is unlikely that they had previously been exposed to a similar H1N1 until the recent pandemic. Sleep deprivation did not influence the antibody titer response to $\mathrm{H} 1 \mathrm{~N} 1$ in females. Moreover, there were no differences between the sleep and sleep deprivation conditions in terms of circulating concentrations of $\mathrm{H} 1 \mathrm{~N} 1$ antibodies at time points later than day 5 . These negative findings should be interpreted with caution inasmuch as they could be caused by the low detection power associated with the relatively low sample size of our study. Thus, these results indisputably require further validation in more studies. Finally, although we obtained EEG measures in five subjects of the sleep group, and thus quantitatively assured that subjects did sleep, we cannot rule out that those whose sleep were not recorded may have deviated from their habitual sleep patterns. However, based on the sleep diaries, all participants, including those who did not undergo EEG recordings, did not report subjective disturbances in their sleep habits.

\section{Conclusions}

Our results suggest that sleep deprivation in the night after vaccination may influence very early phases of an adaptive immune response, as indicated by the lower antibody titer response in sleep-deprived males measured 5 days after vaccination against the H1N1 virus. However, since antibody titers at later time points did not differ between the sleep and sleep deprivation conditions, our results do not support the view that acute sleep deprivation has lasting effects on the human antibody titer response to influenza vaccination.

\section{Methods}

\section{Subjects}

24 healthy non-smoking students participated in the experiment (born after 1986; body-mass- index, range 20-25 kg/m², Table 1). They were assigned to two groups: 'sleep' ( $\mathrm{n}=13 ; 5$ males) or 'sleep deprivation' ( $\mathrm{n}$ $=11 ; 6$ males). The groups did not differ in terms of age or body weight. Acute illness was excluded by physical examination and routine laboratory investigation. During an interview before the study, all participants reported having a regular sleep-wake rhythm (i.e. participants' main sleep periods were between 10:00 PM and 8:00 AM the next morning; no shift work) and none were taking medication (including analgesics such as acetaminophen). Further, to be included in the study it was vital that participants reported, in a thorough interview, to have been free of major influenza-like symptoms in the past 6 months (e.g., high fever, chest congestion, vomiting). The study was approved by the Regional Ethical Review Board (EPN) in Uppsala, Sweden. All participants gave written informed consent and were paid for enrolling in the study.

\section{Experimental design and procedure}

The experimental time schedule is presented in Table 2. All subjects were vaccinated against swine flu $(0.5-\mathrm{mL}$ intramuscular injection, Pandemrix, GlaxoSmithKline, UK) at 7:30 AM on the morning of 27th November 2009. They were not informed about their respective group assignment until 8:00 PM the same day. The electroencephalography (EEG) of five students of the sleep group was continuously recorded in the night after vaccination using an ambulatory amplifier (Embla, Flaga hf, Iceland), and polysomnography (including EMG and EOG) was performed according to standard criteria [15]. 
Table 1 Subjective data

\begin{tabular}{llll}
\hline & & $\begin{array}{l}\text { Sleep } \\
\text { group }\end{array}$ & $\begin{array}{l}\text { Sleep deprivation } \\
\text { group }\end{array}$ \\
\hline Number of subjects & All & 13 & 11 \\
& Women & 8 & 5 \\
& Men & 5 & 6 \\
Age (in years) & All & $20.6 \pm 0.4$ & $20.4 \pm 0.5$ \\
& Women & $21.5 \pm 0.4$ & $20.2 \pm 0.7$ \\
Body weight (in kg) & Men & $19.2 \pm 0.4$ & $20.5 \pm 0.7$ \\
& All & $65.4 \pm 4.9$ & $64.6 \pm 5.7$ \\
C-reactive Protein & Women & $56.9 \pm 6.0$ & $50.2 \pm 7.6$ \\
(mg/L) & Men & $79.0 \pm 3.7$ & $76.7 \pm 4.2$ \\
& & & \\
Ig G (g/L) & All & $0.98 \pm 0.26$ & $1.22 \pm 0.32$ \\
& Women & $0.97 \pm 0.25$ & $1.21 \pm 0.38$ \\
& Men & $0.99 \pm 0.60$ & $1.24 \pm 0.53$ \\
& All & $10.61 \pm$ & $10.5 \pm 0.41$ \\
& & 0.63 & \\
lg $\mathbf{M}$ (g/L) $(\mathbf{g} / \mathbf{L})$ & Women & $10.61 \pm$ & $10.56 \pm 0.70$ \\
& & 0.85 & \\
& Men & $10.60 \pm$ & $10.38 \pm 0.53$ \\
& & 1.04 & \\
& All & $1.99 \pm 0.25$ & $2.10 \pm 0.41$ \\
& Women & $1.82 \pm 0.23$ & $2.13 \pm 0.39$ \\
& Men & $2.28 \pm 0.23$ & $2.07 \pm 0.55$ \\
& All & $1.30 \pm 0.16$ & $1.22 \pm 0.18$ \\
& Women & $1.46 \pm 0.23$ & $1.54 \pm 0.29$ \\
& Men & $1.05 \pm 0.16$ & $0.96 \pm 0.18$ \\
\hline
\end{tabular}

All variables are presented with mean \pm S.E.M. Three days before vaccination, circulating levels of $C$-reactive protein and immunglobulin subclasses $(A, G, M)$ were analyzed by normal laboratory routine. No statistical differences were found between the groups (assessed by Mann-Whitney-U-tests).

Sleep stages were determined off-line by an experienced scorer blinded to the study hypothesis. The subjects in the wake group remained in the sleep laboratory and did not sleep until 6:00 PM the following day. To keep subjects awake, they were provided with a selection of

Table 2 Experimental time schedule.

\begin{tabular}{lcl}
\hline Experimental day & Date & Measurements \\
\hline Day -3 & $2009-11-24$ & Health assessment \\
Day 0 & $2009-11-27$ & H1N1 vaccination \\
& $2009-11-28$ & Sleep diary \\
& $2009-11-29$ & Sleep diary \\
& $2009-11-30$ & Sleep diary \\
& $2009-12-01$ & Sleep diary \\
& $2009-12-02$ & Sleep diary \& Serum antibody titer \\
Day 5 & $2009-12-03$ & Sleep diary \\
& $2009-12-04$ & Sleep diary \\
& $2009-12-05$ & Sleep diary \\
& $2009-12-06$ & Sleep diary \\
Day 10 & $2009-12-07$ & Sleep diary \& Serum antibody titer \\
Day 17 & $2009-12-14$ & Serum antibody titer \\
Day 52 & $2010-01-18$ & Serum antibody titer \\
\hline
\end{tabular}

movies, games, and books and were continuously observed by investigators. Further, the lights were on ( $~ 800$ lux) and the subjects were provided with regular meals. On the day of vaccination and the day after, students of both conditions were not allowed to consume caffeine-containing beverages.

Blood was sampled at 8:00 AM in the morning on days $5,10,17$, and 52 after the vaccination and stored at $-80^{\circ} \mathrm{C}$ until assay. Hemagglutination inhibition (HAI) antibody titers against the H1N1 virus were determined in duplicate. Serum samples were treated with receptordestroying enzyme and then incubated at $56^{\circ} \mathrm{C}$ for 30 min. HAI assays were performed at a starting dilution of 1:10, with subsequent serial -fold dilutions (maximum dilution level, 1:5120). A seroprotective titer for HAI was defined as $1: 40$. Chicken erythrocytes $(0.5 \%)$ were used for the agglutination. All samples from a single participant were tested simultaneously and run in duplicate.

\section{Statistical analysis}

For statistical reasons, the dilution levels deriving from hemagglutination inhibition (HAI) assay were transformed into degrees of dilution. For instance, a HAI dilution level of 1:10 corresponds a degree of dilution of 1 (maximum dilution level, 1:5120 = degree of dilution of 10). Differences between groups were analyzed using Kruskal-Wallis nonparametric analysis with Mann-Whitney $\mathrm{U}$ post hoc testing, and a $\mathrm{P}$ value $\leq 0.05$ was considered statistically significant. Treatment effects were also evaluated separately for the male and female subgroups. All data are presented as means \pm SEM.

\section{Acknowledgements}

We thank Mona Hedenskog (Department of Virolology, Swedish Institute for Infectious Disease Control, Solna, Sweden) for invaluable laboratory assistance and Staffan Sylvan (Department of Medical Sciences, Infectious Diseases, Uppsala University, Uppsala, Sweden) for assisting with planning of the vaccination. We acknowledge fruitful discussion with Dr. Tanja Lange (Department of Neuroendocrinology, University of Luebeck, Germany). The authors' work is funded by the Swedish Research Council, Brain Research Foundation (Sweden), Novo Nordisk (Denmark), Olle Engkvist Byggmästare foundation (Sweden), Tore Nilsons foundation (Sweden), Gunvor och Josef Anérs foundation (Sweden), Åke Wibergs foundation (Sweden), Åhlens foundation (Sweden), and AstraZeneca (Sweden), and Uppsala University (Sweden). The funding sources had no role in the design and conduct of the study; collection, management, analysis, and interpretation of the data; and preparation, review, or approval of the manuscript. All authors had full access to all of the data and take responsibility for the integrity and accuracy of the data analysis. None of the authors has conflicts of interest.

\section{Author details}

'Department of Neuroscience, Uppsala University, Uppsala, Sweden. 2Department of Virology, Swedish Institute for Infectious Disease Control, Solna, Sweden. ${ }^{3}$ Department of Neuroscience, Psychiatry, Sleep Medicine Center, University Hospital, Uppsala, Sweden.

\section{Authors' contributions}

$C B, A M$, and $J B$ carried out the experiments. $M B$ carried out the immunoassays. All authors contributed to writing. $\mathrm{CB}, \mathrm{AM}, \mathrm{JB}$, and $\mathrm{HS}$ designed the study. All authors read and approved the final manuscript. 


\section{References}

1. Spiegel K, Sheridan JF, Van Cauter E: Effect of sleep deprivation on response to immunization. JAMA 2002, 288(12):1471-2.

2. Lange T, Perras B, Fehm HL, Born J: Sleep enhances the human antibody response to hepatitis A vaccination. Psychosom Med 2003, 65(5):831-5.

3. Bryant PA, Trinder J, Curtis N: Sick and tired: Does sleep have a vital role in the immune system? Nat Rev Immunol 2004, 4(6):457-67.

4. Lange T, Dimitrov S, Born J: Effects of sleep and circadian rhythm on the human immune system. Ann N Y Acad Sci 2010, 1193(1):48-59.

5. Lange T, Born J: The immune recovery function of sleep - tracked by neutrophil counts. Brain, Behavior, and Immunity 2011, 25(1):14-5.

6. Irwin M, Clark C, Kennedy B, Gillin CJ, Ziegler M: Nocturnal catecholamines and immune function in insomniacs, depressed patients, and control subjects. Brain Behav Immun 2003, 17(5):365-72.

7. Van Cauter E: Slow wave sleep and release of growth hormone. JAMA 2000, 284(21):2717-8.

8. Sadamatsu M, Kato N, lida H, Takahashi S, Sakaue K, Takahashi K, Hashida S, Ishikawa E: The 24-hour rhythms in plasma growth hormone, prolactin and thyroid stimulating hormone: effect of sleep deprivation. J Neuroendocrinol 1995, 7(8):597-606.

9. Meazza C, Pagani S, Travaglino P, Bozzola M: Effect of growth hormone (GH) on the immune system. Pediatr Endocrinol Rev. Suppl 2004, 3:490-5.

10. Benedict C, Dimitrov S, Marshall L, Born J: Sleep enhances serum interleukin-7 concentrations in humans. Brain Behav Immun 2007, 21(8): 1058-62.

11. Born J, Lange T, Hansen K, Mölle M, Fehm HL: Effects of sleep and circadian rhythm on human circulating immune cells. J Immunol 1997, 158(9):4454-64.

12. Irwin MR, Carrillo C, Olmstead R: Sleep loss activates cellular markers of inflammation: sex differences. Brain Behav Immun 2010, 24(1):54-7.

13. Dimitrov S, Lange T, Nohroudi K, Born J: Number and function of circulating human antigen presenting cells regulated by sleep. Sleep 2007, 30(4):401-11.

14. van Vliet SJ, García-Vallejo JJ, van Kooyk Y: Dendritic cells and C-type lectin receptors: coupling innate to adaptive immune responses. Immunol Cell Biol 2008, 86(7):580-7.

15. Rechtschaffen A, Kales A: A Manual of Standardized Terminology, Techniques and Scoring System for Sleep of Human Subjects. United States Government Printing Office Washington, DC; 1968.

doi:10.1186/1471-2172-13-1

Cite this article as: Benedict et al:: Acute sleep deprivation has no lasting effects on the human antibody titer response following a novel influenza A H1N1 virus vaccination. BMC Immunology 2012 13:1.

\section{Submit your next manuscript to BioMed Central and take full advantage of:}

- Convenient online submission

- Thorough peer review

- No space constraints or color figure charges

- Immediate publication on acceptance

- Inclusion in PubMed, CAS, Scopus and Google Scholar

- Research which is freely available for redistribution

Submit your manuscript at www.biomedcentral.com/submit
Biomed Central 